\section{PENELITIAN PENGARUH CAMPURAN KARET ALAM \\ DAN KARET NITRIL KOMPON SOL SEPATU TERHADAP SIFAT SWELLING}

\author{
Oleh : Sofyan Karani, Niken Karsiati
}

\section{ABSTRACT}

The objective of this research is to find the quality of oil resistant soles indicated by swelling test in Benzol. The compound is made of natural rubber (RSS) and synthetic rubber (NBR) the part of which vary from $45 / 55 ; 50 / 50 ; 55 / 45$. The result of the test indicates that the sole compound of RSS 45 part and NBR 55 part gives the best oil resistant

\section{INTISARI}

Penelitian ini bertujuan untuk mengetahui mutu sol sepatu tahan minyak dengan indikator ui pembengkakian sol dalam larutan bensol. Formulasi kompon dengan menggunakan uji pembeng karet sintetis (NBR) dengan variasi $(45 / 55,50 / 50$ dan 55) campuran karet alam (RSS) dan karet sintetis (NBR) dengan variasi (4ST) satu komposisi RSS 45 bagian dan NBR 55 bagian memberikan sifat ketahanan terhadap minyak yang paling baik.

\section{PENDAHULUAN}

Sol sepatu merupakan salah satu komponen penting didalam menentukan kualitas suatu produk sepatu, apalagi untuk jenis sepatu yang khusus penggunaannya maka akan diperlukan persyaratan-persyaratan tertentu sehingga sepatu tersebut dapat lebih berdaya guna dalam pemakaiannya. Misalnya untuk sepatu yang digunakan pada medan yang berminyak, maka diperlukan sol sepatu yang tahan minyak.

Makin majunya industri manufacture terutama pada industri perkapalan, perbengkelan, permesinan dan lain-lain, maka kebutuhan akan sepatu pengaman yang mempunyai sol tahan minyak akan semakin meningkat pula.

Salah satu bahan baku yang dapat digunakan untuk mendapatkan sol sepatu tahan minyak adalah karet sintetis jenis nitril, karena karet nitril ini mempunyai sifat tidak membengkak (swelling) dalam minyak atau istilah lain adalah memiliki ketahanan terhadap minyak yang baik.

Ketahanan terhadap minyak tergantung pada kadar acrylonitril, yaitu makin tinggi kadar acrylonitril, maka akan semakin tahan terhadap minyak, lemak atau bensin. Umumnya bahan tersebut digunakan antara $18-48 \%$, tetapi bila semakin banyak karet nitril yang digunakan akan menurunkan sifat elastisitas dan akan sulit untuk diplastisasi. Dalam proses vulkanisasi karet nitril memerlukan banyak bahan pencepat dan lebih sedikit belerang apabila dibandingkan dengan proses vulkanisasi karet alam.

Saat ini banyak produk karet yang sudah menggunakan karet nitril sebagai campuran bahan baku karet alamnya, hal ini disebabkan karet alam dan karet sintetis thasing-masing mempunyai kelebihan dan kekurangannya, sehingga apabila dalam proses pembuatan barang karet digunakan kedua bahan tersebut diharapkan produk yang dihasilkan dapat memenuhi persyaratan. Dalam tabel 1. dapat dibaca perbandingan sifat karet alam, karet nitril dan campuran karet nitril karet alam terhadap beberapa perlakuan.

label 1. Sifat karet alam, karet nitril dan campuran keduanya

\begin{tabular}{|c|c|c|c|c|}
\hline No. & Sifat & Karet Alam & Kuret Nitril & $\begin{array}{c}\text { Campuran } \\
\text { Karet Alam } \\
\text { dan } \\
\text { Karet Nitril }\end{array}$ \\
\hline $\begin{array}{l}1 \\
2 \\
3 \\
4\end{array}$ & $\begin{array}{l}\text { Berat Jenis } \\
\text { Ketahanan terhadap sobekan } \\
\text { Ketahanan terhadap gesekan } \\
\text { Ketahanan terhadap pelarut: } \\
\text { - hidrokarbon alifatik } \\
\text { - hidrokarbon aromatik } \\
\text { Ketahanan terhadap asam encer } \\
\text { Ketahanan terhadap asam pekat } \\
\text { Pelarut yang mengandung } \\
\text { oksigen/keton } \\
\text { Daya tahan terhadap: } \\
\text { - minyak dari hewani/nabati } \\
\text { - minyak dan bensin } \\
\text { - api } \\
\text { - suhu dingin } \\
\text { - suhu panas } \\
\text { Oksidasi } \\
\text { Vulkanisasi } \\
\text { Ketahanan terhadap ozon }\end{array}$ & $\begin{array}{c}\text { 0,92 } \\
\text { baik } \\
\text { sangat baik } \\
\text { tidak tahan } \\
\text { tidak tahan } \\
\text { Sedang, baik } \\
\text { sedang, baik } \\
\text { baik } \\
\text { tidak baik/baik } \\
\text { tidak baik } \\
\text { tidak baik } \\
\text { sangat baik } \\
\text { baik } \\
\text { baik } \\
\text { sangat baik } \\
\text { sedang }\end{array}$ & $\begin{array}{l}1,00 \\
\text { sedang } \\
\text { baik } \\
\text { sangat baik } \\
\text { baik } \\
\text { baik } \\
\text { tidak baik } \\
\text { sedang } \\
\text { sangat baik } \\
\text { sangat baik } \\
\text { tidak baik } \\
\text { baik } \\
\text { sangat baik } \\
\text { baik } \\
\text { sangat baik } \\
\text { sedang }\end{array}$ & $\begin{array}{l}\text { 0,94-0,97 } \\
\text { baik } \\
\text { sangat baik } \\
\text { baik } \\
\text { baik } \\
\text { baik } \\
\text { sedang } \\
\text { baik } \\
\text { baik } \\
\text { baik } \\
\text { tidak baik } \\
\text { sangat baik } \\
\text { sangat baik } \\
\text { baik } \\
\text { sangat baik } \\
\text { sedang }\end{array}$ \\
\hline
\end{tabular}

Penelitian ini bertujuan untuk mengetahui mutu sol sepatu tahan minyak dengan indikator uji pembengkakan sol dalam larutan bensol yang merupakan salah waii cara uji untuk mendapatkan sifat ketahanan karet terhadap minyak.

Vol. XII No. 23 Th. 1996/1997 


\section{MATERI DAN METODA}

1. Materi

1.1 Bahan

Bahan yang digunakan dalam penelitian ini adalah Rubber Smoked Sheet (RSS), Acrylonitril Butadiene Rubber (NBR), Reclaimed Rubber (WTR), Zink Oxide, Stearic Acid, Carbon Black, Aluminium Selecit, China Clay, Napthenic Oil, Coumaron Resin, Anti Oxidant, TG, MBTS dan Sulfur. Sedangkan untuk bahan pengujiannya adalah larutan bensol.

1.2 Peralatan

Timbangan, Two Roll Mill, Hydraulic Press, Cetakan, Cutter, Tabung Reaksi, Stop Watch, Curometer dan Mistar.

2. Metoda

2.1 Prosedur penelitian

Dalam pembuatan kompon sol karet, bahan baku dan bahan pembantu yang sudah ditimbang dicampur dengan menggunakan alat two roll mill (giling karet terbuka) sampai homogen. Kemudian kompon dimasukkan dalam cetakan untuk divulkanisasi menggunakan hydraulic press dengan kondisi suhu 150 SYMBOL 176 \f "Symbol"C, tekanan $150 \mathrm{~kg} / \mathrm{cm} 2$ dan waktu 9 menit.

\subsection{Pengujian}

Kompon yang sudah divulkanisasi kemudian dibuat cuplikan untuk dilakukan uji pembengkakan dalam larutan bensol dengan cara sebagai berikut :

- Buat cuplikan sebanyak 3 buah dengan ukuran masing-masing panjang = $10 \mathrm{~mm}$, lebar $=2 \mathrm{~mm}$ dan tebal $=2 \mathrm{~mm}$.

- Masukkan dalam tabung reaksi yang berisi larutan bensol, tutup rapat-rapat dengan penutup gabus, kemudian letakkan tabung tersebut pada rak tabung reaksi dengan kemiringan 45SYMBOL 176 \f "Symbol". Diamkan selama waktu yang ditentukan.

- Setelah waktu yang ditentukan, cuplikan diambil kemudian diukur perubahan panjang (P1) dengan menggunakan mistar baja.

- Pengukuran cuplikan dilakukan 6 kali pada selang waktu : $0^{\prime}, 30^{\prime}, 60^{\prime}, 180^{\prime}$, $240^{\prime}$ dan 24 jam setelah perendaman.

Perhitungan pembengkakan :

Pembengkakan $=\frac{\mathrm{P}_{1}{ }^{3}-\mathrm{P}_{0}{ }^{3}}{\mathrm{P}_{0}{ }^{3}} \times 100 \%$

$\mathrm{P} 0$ = panjang cuplikan mula-mula $(\mathrm{mm})$

$\mathrm{P} 1$ = panjang cuplikan sesudah pembengkakan $(\mathrm{mm})$

\section{IIASIL DAN PEMBAHASAN}

Hasil penelitian merupakan hasil uji rata-rata pembengkakan kompon sol iepatu karet tahan minyak (kompon vulkanisat) setelah direndam dalam bensol. Variasi campuran bahan baku RSS dan NBR adalah 45/55; 50/50; 55/45. Sedangkan variasi waktu perendaman dalam bensol adalah 0', 30', 60', 180', 240' dan 24 jam.

Tabel 2. Hasil uji rata-rata pembengkakan kompon vulkanisat dengan campuran RSS $45 \%$ dan NBR 55\%.

\begin{tabular}{|c|c|c|c|c|c|c|c|}
\hline \multirow{2}{*}{$\begin{array}{c}\text { Carbon } \\
\text { Black }\end{array}$} & \multirow[t]{2}{*}{ Silikat } & \multicolumn{6}{|c|}{ Persentase pembengkakan setelah $\mathrm{X}$ menit (\%) } \\
\hline & & $0^{\prime}$ & $30^{\prime}$ & $60^{\prime}$ & $180^{\prime}$ & $240^{\prime}$ & 24 jam \\
\hline \multirow{6}{*}{25} & & 211,214 & 100,038 & 58,117 & 22,504 & 9.273 & $-2,980$ \\
\hline & 15 & 217.650 & 104.838 & 50.112 & 14.102 & 10.872 & $-4,433$ \\
\hline & & 217,650 & 107,267 & 48.154 & 14,102 & 9,272 & -5.881 \\
\hline & & 211,214 & 97,656 & 54,080 & 22,502 & 12,486 & $-4,433$ \\
\hline & $\Sigma x$ & 857,728 & 409,799 & 210,463 & 73,210 & 41,903 & $-17,727$ \\
\hline & $\bar{x}$ & 192,420 & 83,826 & 52,088 & 20,795 & 14,116 & $-4,433$ \\
\hline \multirow[t]{5}{*}{25} & 30 & 198,364 & 83,826 & 54,080 & 19,102 & 12,486 & 4,433 \\
\hline & & 198,364 & 83,826 & 58,117 & 22,504 & 14,116 & $-5,881$ \\
\hline & & 192,420 & 83,826 & 56,089 & 22,504 & 14,116 & $-4,433$ \\
\hline & $\Sigma x$ & 763,568 & 335,304 & 220,374 & 84,905 & 54,834 & $-19,180$ \\
\hline & $\bar{x}$ & 190,892 & 83,826 & 55,094 & 21,226 & 13,709 & $-4,795$ \\
\hline \multirow{6}{*}{25} & & 201,720 & 92,978 & 68,516 & 24,330 & 15,763 & $-4,433$ \\
\hline & 25 & 198,578 & 95,315 & 68,516 & 25,971 & 15,763 & $-4,433$ \\
\hline & & 204,863 & 90,663 & 52,088 & 25,971 & 14,116 & $-4,433$ \\
\hline & & 201,720 & 90,663 & 58,117 & 24,330 & 15,763 & $-2,470$ \\
\hline & $\sum x$ & 806,881 & 369,619 & 247,237 & 100,602 & 61,405 & $-16,269$ \\
\hline & $\bar{x}$ & 201,702 & 92,405 & 61,809 & 25,150 & 15,351 & $-4,067$ \\
\hline
\end{tabular}


Tabel 3. Hasil uji rata-rata pembengkakan kompon vulkanisat dengan campuran RSS $50 \%$ dan NBR $50 \%$.

\begin{tabular}{|c|c|c|c|c|c|c|c|}
\hline \multirow{2}{*}{$\begin{array}{c}\text { Carbon } \\
\text { Black }\end{array}$} & \multirow{2}{*}{ Silikat } & \multicolumn{6}{|c|}{ Persentase pembengkakan setelah X menit (\%) } \\
\hline & & $0^{\prime}$ & $30^{\prime}$ & $60^{\prime}$ & $180^{\prime}$ & $240^{\prime}$ & $24 \mathrm{jam}$ \\
\hline \multirow{4}{*}{25} & \multirow{4}{*}{15} & 189,364 & 100,038 & 58,117 & 25,971 & 12,486 & $-4,433$ \\
\hline & & 192,421 & 104,838 & 64,303 & 31,293 & 14,117 & $-4,433$ \\
\hline & & 186,329 & 102,429 & 58,117 & 25,971 & 10,872 & $-4,433$ \\
\hline & & 147,400 & 95,413 & 56,089 & 27,729 & 12,486 & $-5,881$ \\
\hline \multirow[t]{3}{*}{. } & $\sum x$ & 742,514 & 402,618 & 236,626 & 110,964 & 49,961 & -19.180 \\
\hline & $\overline{\mathrm{x}}$ & 185,628 & 100,618 & 59,157 & 27,741 & 12,490 & $-19,180$ \\
\hline & \multirow{4}{*}{20} & 195.598 & 119.700 & 68.516 & 34.923 & 17.428 & -4.433 \\
\hline \multirow[t]{5}{*}{25} & & 204,863 & 119.700 & 62.223 & 24.503 & 12.486 & $-5,881$ \\
\hline & & 192.421 & 119.700 & 66.406 & 33.100 & 14.117 & -5.881 \\
\hline & & 204.863 & 109.715 & 56,089 & 27.729 & 12.480 & -2.970 \\
\hline & $\sum x$ & 800.745 & 468,815 & 253,234 & 120,255 & 56.511 & $-19,165$ \\
\hline & $\bar{x}$ & 200,186 & 117,204 & 63,309 & 30,064 & 14,128 & $-4,791$ \\
\hline \multirow{6}{*}{25} & \multirow{4}{*}{25} & 214,422 & 102,429 & 52,088 & 24,230 & 12,486 & $-4,433$ \\
\hline & & 195,499 & 107,267 & 54,080 & 27,729 & 14,117 & $-4,433$ \\
\hline & & 195,499 & 112,182 & 54,080 & 25,971 & 15,763 & $-4,970$ \\
\hline & & 196,329 & 104,838 & 48,154 & 25,971 & 12,486 & $-4,433$ \\
\hline & $\sum x$ & 791,749 & 426,716 & 208,402 & 103,901 & 58,852 & $-18,269$ \\
\hline & $\bar{x}$ & 197,937 & 106,679 & 52,101 & 25,975 & 13,713 & $-4,567$ \\
\hline
\end{tabular}

Tabel 4. Hasil uji rata-rata pembengkakan kompon vulkanisat dengan campuran RSS $55 \%$ dan NBR $45 \%$.

\begin{tabular}{|c|c|c|c|c|c|c|c|}
\hline \multirow{2}{*}{$\begin{array}{c}\text { Carbon } \\
\text { Black }\end{array}$} & \multirow[t]{2}{*}{ Silikat } & \multicolumn{6}{|c|}{ Persentase pembengkakan setelah X menit (\%) } \\
\hline & & $0^{\prime}$ & $30^{\prime}$ & $60^{\circ}$ & $180^{\prime}$ & $240^{\prime}$ & 24 jam \\
\hline \multirow{6}{*}{25} & . & 201,720 & 117,175 & 62,223 & 27,729 & 12,486 & $-4,433$ \\
\hline & 15 & 204,863 & 124,809 & 66,401 & 29,503 & 10,872 & $-4,433$ \\
\hline & & 204,863 & 124,809 & 68,516 & 31,293 & 12,486 & $-4,433$ \\
\hline & & 198,598 & 117,175 & 62,223 & 27,729 & 12,486 & $-2,970$ \\
\hline & $\Sigma x$ & 810,044 & 483,968 & 259,413 & 116,254 & 48,330 & $-16,268$ \\
\hline & $\overline{\mathrm{x}}$ & 202,511 & 120,992 & 64,853 & 29,064 & 12,083 & $-4,067$ \\
\hline \multirow{6}{*}{25} & & 189,364 & 107,267 & 60,161 & 37,729 & 12.486 & -4.433 \\
\hline & 20 & 192.421 & 119.700 & 70,849 & 23,100 & 14.117 & $-2,970$ \\
\hline & & 192.421 & 107.267 & 56,089 & 22,504 & 10.872 & $-3,881$ \\
\hline & & 192,421 & 104,838 & 54,080 & 24,230 & 10,872 & $-4,433$ \\
\hline & $\Sigma x$ & 766,627 & 439,072 & 244,188 & 107,563 & 48,347 & $-15,717$ \\
\hline & $\bar{x}$ & 191.657 & 109,768 & 61,047 & 26,891 & 12,087 & $-3,929$ \\
\hline \multirow{6}{*}{25} & & 204,863 & 104,838 & 44,289 & 22,504 & 12,486 & $-4,433$ \\
\hline & 25 & 208,027 & 107,267 & 50,112 & 20,795 & 12,486 & $-5,881$ \\
\hline & & 208,027 & 109,715 & 50,112 & 22,504 & 12,486 & $-3,314$ \\
\hline & & 201,720 & 107,267 & 50,112 & 22,504 & 10,872 & $-5,881$ \\
\hline & $\sum x$ & 822,637 & 429.087 & 194.625 & 88,307 & 48,330 & $-12,509$ \\
\hline & $\bar{x}$ & 205,659 & 107,272 & 48,656 & 22,077 & 12,083 & $-4,877$ \\
\hline
\end{tabular}

\section{PEMBAHASAN}

Berdasarkan hasil pengujian sampai waktu 24 jam seteiah perendaman, ierlihat bahwa persentase pembengkakan (swelling) semakin kecil hingga mencapai iekitar - 4\%, hal ini dapat terlihat dari kompon sol sepatu yang sudah mulai mengalami penyusutan/pengkerutan setelah perendaman dalam larutan bensol hingga volume semula. Keadaan seperti ini dapat terjadi disebabkan karena sifat dari elastomer karet yang apabila kontak dengan larutan (dalam hal ini bensol) akan cenderung mengabsorpsi sejumlah tertentu larutan untuk rongga antar jaringan karet, sehingga elastomer itu akan mengembang. Tetapi apabila proses pembengkakan (swelling) sudah maksimal dan kemudian sudah tidak lagi kontak dengan larutan, maka akan terjadi penguapan dari larutan yang diserap, sehingga akibatnya akan terjadi pengkerutan atau penyusutan.

Berdasarkan data uji terdapat pada tabel 2, 3 dan 4 terlihat bahwa rata-rata jersentase pembengkakan yang paling kecil terjadi pada kompon sol sepatu menggunakan bahan baku RSS dan NBR dengan perbandingan $45 \%: 55 \%$. Hal ini menunjukkan bahwa kompon tersebut mempunyai sifat ketahanan terhadap minyak yang lebih tinggi atau lebih baik dibanding dengan kompon yang menggunakan variasi campuran RSS dan NBR ( $50 / 50$ atau 55/45) \%. Sifat ketahanan terhadap 
minyak ỳang baik tersebut disebabkan oleh semakin banyaknya penggunaan karet sintetis jenis nitril (NBR) dalam pembuatan kompon sol sepatu. Karet NBR ini merupakan jenis karet sintetis yang tinggi kadar acrylonitrilnya, yang mana kadar acrylonitril tersebut akan berpengaruh terhadap sifat tahan minyak, yaitu apabila semakin tinggi kadar akrilonitrilnya, maka akan semakin tahan pula terhadap minyak atau lemak.

\section{KESIMPULAN}

Berdasarkan hasil penelitian dapat disimpulkan sebagai berikut :

- Penggunaan karet sintetis jenis Acrylonitril Butadiene Rubber (NBR) dalam pembuatan kompon sol sepatu dapat memperbaiki sifat ketahanan terhadap minyak.

- Makin banyak jumlah karet NBR yang digunakan akan semakin baik sifat ketahanan terhadap minyak.

\section{PUSTAKA}

1. Anonimous, Rubber Technology and Manufacture, SPB Board of Consultant and Engineers, Roop Nagar, Delhi.

2. Japanese Industrial Standard, Physical Testing Methods for Vulcanized Rubber, JIS K 6301 - 1973.

3. Prayitno dkk, Penelitian Pembuatan Sol Untuk Pintu Air, Proceedings Pertemuan Teknis Pengembangan Produksi Barang Karet, BBKKP, Yogyakarta, 1992. 4. Suwarti Suseno, Pedoman pengujian sifat fisika barang jadi karet, BPP Bogor, Menara Perkebunan, 1978. 